\title{
Analisis Komponen Fisik Terhadap Kemampuan Menggiring Bola Permainan Sepakbola Sma Negeri 11 Makassar
}

\author{
Achmad Karim, Muhammad Hasbillah \\ Pendidikan Jasmani, Kesehatan dan Rekreasi. STKIP YPUP Makassar \\ achmad.karim90@gmail.com
}

Received: Januari 2021; Accepted: Maret 2021; Published: Maret 2021

Ed: Maret 2021; 8(1): 77-86

\begin{abstract}
Abstrak
Penelitian ini adalah jenis penelitian deskriptif yang menggunakan rancangan penelitian "korelasional". Populasinya adalah keseluruhan siswa SMA Negeri 11 Makassar. Sampel yang digunakan adalah sebanyak 30 orang. Teknik penentuan sampel adalah dengan pemilihan secara acak (simple random sampling). Teknik analisis data yang digunakan adalah analisis deskriptif, analisis koefisien korelasi pearson product moment (r), dan hasil analisis korelasi ganda (R) pada taraf signifikan $\alpha=0,05$. Hasil penelitian menunjukkan bahwa; (1) Ada hubungan yang signifikan koordinasi mata kaki terhadap kemampuan menggiring bola pada permainan sepak bola Siswa SMA Negeri 11 Makassar, dengan nilai $r=0,561(\rho<\alpha=0,05)$; (2) Ada hubungan yang signifikan keseimbangan terhadap kemampuan menggiring bola pada permainan sepak bola Siswa SMA Negeri 11 Makassar, dengan nilai $r$ $=0,603(\rho<\alpha=0,05)$; (3) Ada hubungan yang signifikan kekuatan otot tungkai terhadap kemampuan menggiring bola pada permainan sepak bola Siswa SMA Negeri 11 Makassar, dengan nilai $r=0,728(\rho<\alpha=0,05)$; (4) Ada hubungan yang signifikan secara bersama-sama antara koordinasi mata kaki, keseimbangan dan kekuatan otot tungkai terhadap kemampuan menggiring bola pada permainan sepak bola Siswa SMA Negeri 11 Makassar, dengan nilai koefisien determinan $(\mathrm{R} 2)=0,733$ atau $73,3 \%$.
\end{abstract}

Kata Kunci: koordinasi mata kaki, keseimbangan, kekuatan otot tungkai, menggiring bola.

\begin{abstract}
This research is a descriptive study using a correlational research design. The population is all students of SMA Negeri 11 Makassar. The sample used was 30 students. The sampling technique was simple random sampling. The data analysis technique used is descriptive analysis, pearson product moment correlation coefficient analysis $(r)$, and the results of multiple correlation analysis $(R)$ at the significant level $\alpha=0.05$. The results showed that; (1) There is a significant relationship between ankle coordination and dribbling ability in soccer game for student of SMA Negeri 11 Makassar, with a value of $r=0,561 \quad(\rho<\alpha=0.05)$; (2) There is a significant relationship between balance and dribbling ability in soccer game for student of SMA Negeri 11 Makassar, with a value of $r=$ 0,603 ( $\rho<\alpha=0.05)$; (3) There is a significant relationship between leg muscle strenght and dribbling ability in soccer game for student of SMA Negeri 11 Makassar, with a value of $r=0,728(\rho<\alpha=0.05)$; (4) There is a significant relationship simultaneously between ankle coordination, balance, leg muscle strenght and dribbling ability in soccer game for student of SMA Negeri 11 Makassar, with a determinant coefficient value $(R 2)=0,733$ or $73,3 \%$.
\end{abstract}

Keywords: ankle coordination, balance, leg muscle strenght and dribbling.

\section{PENDAHULUAN}

Pendidikan jasmani adalah proses pendidikan yang memanfaatkan aktivitas jasmani yang direncanakan secara sistematik bertujuan mengembangkan dan meningkatkan individu secara organik, neuromuskuler, perseptual, kognitif, dan emosional, dalam kerangka sistem pendidikan 
nasional. (Dini Rosdiani (2014:137). Sepak bola adalah suatu permainan yang dimainkan di lapangan berumput dan menggunakan bola dalam permainannya. dimainkan oleh dua tim yang saling berhadapan masing-masing tim beranggotakan sebelas orang pemain.bola di mainkan menggunakan kaki,saling oper dengan rekan satu tim menjaga agar bola tidak direbut lawan,dan tujuan akhirnya memasukan bola kegawang lawan. Pihak yang lebih banyak mencetak gol dialah yang memenangkan permainan.

Teguh Sutanto (2016:172) teknik dasar dalam permainan sepak bola terdiri dari berapa gerakan. Kemampuan seseorang dalam mempermainkan bola sangatlah berguna untuk suatu pertandingan yang berkualitas. teknik dasar dalam permainan sepak bola antara lain: (1) Teknik dasar menendang bola, (2) Teknik dasar menahan bola (trapping), (3) Teknik dasar menggiring bola (dribbling), (4) Teknik gerak tipu, (5) Teknik dasar menyundul bola (heading),(6) Teknik dasar merebut bola (tackling), (7) Teknik dasar lemparan ke dalam. secara khusus teknik menggiring bola memiliki peran penting dalam permainan sepak bola. teknik menggiring bola (dribiling) merupakan keterampilan penting dan mutlak harus di kuasai oleh setiap pemain sepak bola. Menggiring (dribiling) merupakan kemampuan yang di miliki pemain dalam menguasai bola sebelum di berikan kepada temanya untuk menciptakan peluang dalam mencetak gol.

Salah satu Teknik yang diperlukan dalam sepak bola adalah teknik menggiring bola (dribbling). yang perlu dilatih dengan baik, disamping untuk menghindari dan melakukan gerak tipu untuk mengecoh lawan saat menguasai bola perlu memiliki kelentukan dan reaksi untuk melakukan gerakan mengecoh, mengontrol, menghindari segapan lawan dan mengoperkan bola sesuai dengan yang diinginkan pemain.

Menggiring bola tidak hanya membawah bola menyusuri tanah dan lurus kedepan melainkan menghadapi lawan yang jaraknya cukup dekat dan rapat. hal ini menuntut seorang pemain harus memiliki kemampuan menggiring bola dengan baik. Dribbling berguna untuk melewati lawan, mencari kesempatan memberi umpan kepada kawan dan untuk menahan bola tetap dalam penguasaan. Dribbling memerlukan keterampilan yang baik dan dukungan dari unsur unsur kondisi fisik yang baik pula seperti keseimbangan dan kelincahan dapat memberikan kemampuan gerak lebih cepat.

Sepakbola merupakan salah satu mata kuliah yang paling di minati oleh mahasiswa. hal ini terbukti dari antusias mahasiswa untuk mengikuti mata kuliah sepak bola. tetapi tidak semua mahasiswa memiliki kemampuana keterampilan dasar yang baik, terutama teknik menggiring bola (dribiling). Berdasarkan hasil observasi, peneliti melihat masih ada beberapa mahasiswa yang pada saat melakukan kemampuan menggiring bola kurang baik. Pertama, perkenaan kaki dan bola tidak tepat sehingga arah bola susah dikendalikan. Kedua, pandangan mata saat menggiring bola melihat ke arah bola terus.

\section{METODE}

Jenis penelitian yang digunakan peneliti adalah, penelitian korelasi atau korelasional adalah suatu penelitian untuk mengetahui hubungan antara dua variabel atau lebih tanpa ada upaya untuk mempengaruhi variabel tersebut sehingga tidak terdapat manipulasi variabel (Fankel dan Wallen, 2008:328), dalam (Kusumawati, 2015:49), adanya hubungan dan tingkat variabel ini penting karena dengan mengetahui tingkat atau hubungan yang ada, penelitian akan dapat mengembangkannya sesuai dengan tujuan penelitian. penelitian korelasional menggunakan instrumen untuk menentukan apakah, dan untuk tingkat apa, terdapat hubungan antara dua variabel atau lebih yang dapat dikuantitatifkan. 
Metodelogi merupakan teknik yang dipergunakan untuk mencari suatu pembuktian secara ilmiah yang dilakukan secara sistematis guna mengungkapkan dan memberikan jawaban atas permasalahan yang dikemukakan dalam penelitian sehingga arah dan tujuan pengungkapan fakta atau kebenaran sesuai dengan apa yang dikemukakan dalam penelitian. Sejalan dengan hal tersebut, Winarno surahman (1982: 86) menjelaskan bahwa: "Metode merupakan cara yang dipergunakan untuk mencapai suatu tujuan, misalnya untuk serangkaian hipotesis dengan mempergunakan teknik serta alat bantu".

Menurut Uhar Suharsaputra ( 2018 : 49 ), penelitian kuantitatif adalah penelitian yang menggunakan angka-angka yang dijumlahkan sebagai data yang kemudian dianalisis. Sedangkan menurut Sugiyono ( 2018 : 15 ), Penelitian kuantitatif dapat diartikan sebagai metode penelitian yang berlandaskan pada filsafat positifisme, digunakan untuk meneliti pada populasi atau sampel tertentu, pengumpulan data menggunakan instrumen penelitian, analisis data bersifat kuantitatif/statistik, yang bertujuan untuk menggambarkan dan menguji hipotesis yang telah ditetapkan.

\section{Variabel penelitian}

Ada dua variabel yang terlibat dalam penelitian ini yaitu variabel bebas dan variabel terikat. studi ini akan mendefinisikan kedua variabel ini sebagai berikut :

a. Variabel bebas yaitu: Koordinasi mata kaki, Keseimbangan, Kekuatan otot tungkai

b. Variabel terikat yaitu: Kemampuan menggiring bola

\section{Populasi}

Populasi adalah wilayah generalisasi yang terdiri atas objek atau subjek yang mempunyai kuanitas dan karakteristik tertentu yang di tetapkan oleh penelitian untuk di pelajari dan kemudian di tarik kesimpulnya, jadi populasi bukan hanya orang, tetapi juga objek dan benda-benda alam yang lain. populasi juga bukan hanya sekedar jumlah yang ada pada objek atau subjek yang di pelajari, tetapi meliputi seluruh karakteristik atau sifat yang di miliki oleh subjek atau objek yang diteliti (Sugiyono, 2015:92), adapun populasi dalam penelitian ini adalah seluruh siswa SMA Negeri 11 Makassar dengan jumlah 255 orang.

\section{Sampel}

Menurut (Sugiyono, 2015:93), sampel adalah bagian dari jumlah dan karateristik yang di miliki oleh populasi. dalam penelitian ini sampel yang digunakan adalah siswa laki-laki SMA Negeri 11 Makassar yang berjumlah 30 orang menggunakan teknik Random Sampling untuk pengambilan sampel.

\section{Definisi operasional variabel}

Variabel adalah objek penelitian, atau apa yang menjadi titik perhatian suatu penelitian (Arikunto, 2013:161), Dalam penelitian ini ada dua variabel bebas dan satu variabel terikat a. Koordinasi mata-kaki

Koordinasi mata-kaki adalah sebagai suatu hubungan yang harmonis dari hubungan yang saling berpengaruh diantara kelompok-kelompok otot selama aktifitas, yang di tunjungkan berbagai tingkat keterampilan yang akan diukur dengan menendang bola ketembok yaitu seberapa banyak menendang bola yang bisa kena atau tepat sasaran dan berhasil kembali dalam waktu 30 detik

b. Keseimbangan

Keseimbangan adalah kemampuan sesorang dalam mempertahankan sikap dan posisi tubuh secara cepat pada saat berdiri (static balance) atau pada saat melakukan gerakan (dynamic 
balance), yang akan diukur dengan modified bass test of dyamic balance.

c. Kekuatan otot tungkai

Kekuatan otot merupakan kemampuan otot atau sekelompok otot untuk mengatasi suatu beban atau tahanan dalam menjalankan suatu aktifitas. Kekuatan yang di maksud dalam penelitian ini adalah kemampuan otot tungkai untuk melakukan keterampilan menggiring bola pada permainan, sepak bola yang di ukur dengan menggunakan tes Half-Squet Jump

d. Keterampilan menggiring bola

Keterampilan menggiring bola (dribbling) adalah melakukan gerakan menendang secara terputus-putus dan di lakukan secara perlahan-lahan menggiring bola dapat dilakukan dengan kaki bagian dalam, punggung kaki dan kaki bagian luar, yang akan diukur dengan tes zig-zag atau menggiring bola menghindari rintangan waktu di catat sampai persepuluh detik.

\section{HASIL DAN PEMBAHASAN}

\section{Deskripsi Data}

Untuk mendapatkan gambaran umum data suatu penelitian maka digunakanlah analisis data deskriptif terhadap koordinasi mata kaki, keseimbangan dan kekuatan otot tungkai terhadap kemampuan menggiring bola pada permainan sepak bola siswa SMA Negeri 11 Makassar. Hasil analisis deskriptif data tersebut dapat dilihat pada tabel berikut

Tabel 1. Hasil analisis deskriptif

\begin{tabular}{|c|c|c|c|c|}
\hline \multirow{2}{*}{ Statistik } & \multicolumn{4}{|c|}{ Variabel } \\
\cline { 2 - 5 } & $\begin{array}{c}\text { Koordinasi } \\
\text { Mata Kaki } \\
\left(\mathrm{X}_{1}\right) \text { Kali }\end{array}$ & $\begin{array}{c}\text { Keseimbangan } \\
\left(\mathrm{X}_{2}\right) \text { poin }\end{array}$ & $\begin{array}{c}\text { Kekuatan } \\
\text { Otot Tungkai } \\
\left(\mathrm{X}_{3}\right) \text { kali }\end{array}$ & $\begin{array}{c}\text { Menggiring bola } \\
\text { pada permainan } \\
\text { sepak bola }(\mathrm{Y}) \text { detik }\end{array}$ \\
\hline $\mathrm{N}$ & 30 & 30 & 30 & 30 \\
\hline Mean & 14.83 & 79.57 & 19.53 & 18.4693 \\
\hline Median & 15.00 & 79.00 & 19.50 & 18.4100 \\
\hline Mode & 13 & 79 & 16 & 18.14 \\
\hline $\begin{array}{c}\text { Std. } \\
\text { Deviation }\end{array}$ & 1.683 & 4.523 & 2.688 & 1.31532 \\
\hline Variance & 2.833 & 20.461 & 7.223 & 1.730 \\
\hline Range & 6 & 15 & 9 & 5.02 \\
\hline Minimum & 12 & 72 & 15 & 16.19 \\
\hline Maximum & 18 & 87 & 24 & 21.21 \\
\hline Sum & 445 & 387 & 586 & 554.08 \\
\hline
\end{tabular}




\section{Uji Normalitas Data}

Sebelum melakukan uji statistik, salah satu asumsi yang harus dipenuhi adalah data harus mengikuti sebaran normal, maka dilakukan uji normalitas data.Pengujian normalitas data dapat dilakukan untuk mengetahui apakah data yang diperoleh pada hasil penelitian berada pada sebaran normal. Pengujian normalitas data dapat dilakukan dengan uji Kolmogorov Smirnov.

Kriteria untuk menyatakan apakah data berasal dari sampel yang digunakan berdistribusi normal atau tidak dapat dilakukan dengan membandingkan koefisien Sig. Atau nilai P dengan 0,05 (taraf Signifikan). Apabila nilai $\mathrm{P}$ lebih besar dari 0,05 (taraf signifikan) yang berarti tidak signifikan, maka memiliki makna bahwa data berasal dari populasi yang berdistribusi normal. Sebaliknya apabila P-Value lebih kecil dari 0.05, maka memiliki makna bahwa data berasal dari populasi yang berdistribusikan tidak normal

Tabel 2. Hasil Pengujian normalitas

\begin{tabular}{|l|c|c|c|c|}
\hline \multicolumn{1}{|c|}{ Variabel } & KS-Z & $P$ & Sig. & Keterangan \\
\hline Koordinasi Mata Kaki & 0,574 & 0,897 & 0,05 & Normal \\
\hline Kekuatan Otot Tungkai & 0,599 & 0,865 & 0,05 & Normal \\
\hline Daya Ledak Otot Tungkai & 0,645 & 0,800 & 0,05 & Normal \\
\hline $\begin{array}{l}\text { Shooting pada permainan sepak } \\
\text { bola }\end{array}$ & 0,721 & 0,676 & 0,05 & Normal \\
\hline
\end{tabular}

\section{Pengujian Hipotesis}

Setelah dilakukan uji persyaratan normalitas data pada hipotesis yang akan di uji, maka selanjutnya dilakukan pengujsian terhadap hipotesis, untuk membuktikan kebenarannya. Hasil perhitungan statistik pada hipotesis penelitian diuraikan sebagai berikut:

\section{Hubungan koordinasi mata kaki terhadap kemampuan menggiring bola pada permainan sepak bola siswa SMA Negeri 11 Makassar.}

Hipotesis yang pertama diuji dalam penelitian ini yaitu "ada hubungan koordinasi mata kaki terhadap kemampuan menggiring bola pada permainan sepak bola siswa SMA Negeri 11 Makassar", untuk mengetahui kebenarannya maka perlu dilakukan pengujian analisis korelasi tunggal

Tabel 3 Hasil uji korelasi

\begin{tabular}{|c|c|c|c|c|}
\hline Variabel & $\mathrm{N}$ & $r$ & $P_{\text {value }}$ & Keterangan \\
\hline $\begin{array}{l}\text { Koordinasi mata kaki }\left(\mathrm{X}_{1}\right) \\
\text { terhadap menggiring bola pada } \\
\text { permainan sepak bola }(\mathrm{Y})\end{array}$ & 30 &,- 561 & 0,000 & Signifikan \\
\hline
\end{tabular}

Keterangan:

$\mathrm{R}=$ Koefisien Korelasi Tunggal

Pvalue $=$ Nilai Probabilitas

$\mathrm{N} \quad=$ Banyaknya Data 
Secara statistik hipotesis dapat dirumuskan sebagai berikut:

H_0:rx_1 y=0

H_1:rx_1 y $\neq$

Berdasarkan hasil analisis korelasi diperoleh nilai sebesar -561. Dengan demikian hubungan koordinasi mata kaki terhadap menggiring bola pada permainan sepak bola siswa SMA Negeri 11 Makassar menunjukkan bahwa terdapat hubungan yang signifikan.

Hubungan keseimbangan terhadap menggiring bola pada permainan sepak bola siswa SMA Negeri 11 Makassar.

Hipotesis yang kedua diuji dalam penelitian ini yaitu "ada hubungan keseimbangan terhadap kemampuan menggiring bola pada permainan sepak bola siswa SMA Negeri 11 Makassar", untuk mengetahui kebenarannya maka perlu dilakukan pengujian analisis korelasi tunggal.

Tabel 4 Hasil uji korelasi

\begin{tabular}{|c|c|c|c|l|}
\hline Variabel & $N$ & $R$ & $P_{\text {value }}$ & Keterangan \\
\hline $\begin{array}{l}\text { Keseimbangan }\left(\mathrm{X}_{2}\right) \text { terhadap } \\
\text { kemampuan menggiring bola } \\
\text { pada permainan sepak bola }(\mathrm{Y})\end{array}$ & 30 &,- 603 & 0,000 & Signifikan \\
\hline
\end{tabular}

Keterangan:

$\mathrm{r} \quad=$ Koefisien Korelasi Tunggal

Pvalue $=$ Nilai Probabilitas

$\mathrm{N} \quad=$ Banyaknya Data

Secara statistik hipotesis dapat dirumuskan sebagai berikut:

H_0:rx_(2.) $\mathrm{y}=0$

H_1:rx_(2.) y $\neq$ )

Berdasarkan hasil analisis korelasi diperoleh nilai sebesar -,603. Dengan demikian hubungan keseimbangan terhadap kemampuan menggiring bola pada permainan sepak bola siswa SMA Negeri 11 Makassar menunjukkan bahwa terdapat hubungan yang signifikan.

Hubungan kekuatan otot tungkai terhadap kemampuan menggiring bola pada permainan sepak bola siswa SMA Negeri 11 Makassar.

Hipotesis yang pertama diuji dalam penelitian ini yaitu "ada hubungan kekuatan otot tungkai terhadap kemampuan menggiring bola pada permainan sepak bola siswa SMA Negeri 11 Makassar", untuk mengetahui kebenarannya maka perlu dilakukan pengujian analisis korelasi tunggal 
Tabel 5 Hasil uji korelasi

\begin{tabular}{|l|c|c|c|l|}
\hline Variabel & $\mathrm{N}$ & $r$ & $\mathrm{P}_{\text {value }}$ & Keterangan \\
\hline $\begin{array}{l}\text { Kekuatan otot tungkai }\left(\mathrm{X}_{3}\right) \\
\text { terhadap menggiring bola pada } \\
\text { permainan sepak bola }(\mathrm{Y})\end{array}$ & 30 &,- 728 & 0,000 & Signifikan \\
\hline
\end{tabular}

Keterangan:

$\mathrm{r} \quad=$ Koefisien Korelasi Tunggal

Pvalue $=$ Nilai Probabilitas

$\mathrm{N} \quad=$ Banyaknya Data

Secara statistik hipotesis dapat dirumuskan sebagai berikut:

H_0:rx_1 y=0

H_1:rx_1 y $\#$

Berdasarkan hasil analisis korelasi diperoleh nilai sebesar -728. Dengan demikian hubungan kekuatan otot tungkai terhadap menggiring bola pada permainan sepak bola siswa SMA Negeri 11 Makassar menunjukkan bahwa terdapat hubungan yang signifikan.

Hubungan koordinasi mata kaki, keseimbangan dan kekuatan otot tungkai secara bersamasama terhadap kemampuan menggiring bola pada permainan sepak bola siswa SMA Negeri 11 Makassar

Hipotesis yang ketiga diuji dalam penelitian ini yaitu "ada hubungan koordinasi mata kaki, keseimbangan dan kekuatan otot tungkai terhadap kemampuan menggiring bola pada permainan sepak bola siswa SMA Negeri 11 Makassar", untuk mengetahui kebenarannya maka perlu dilakukan pengujian analisis regresi ganda.

Tabel 6 Hasil uji korelasi ganda

\begin{tabular}{|l|c|c|c|c|c|c|}
\hline \multicolumn{1}{|c|}{ Variabel } & $\mathrm{N}$ & $\mathrm{R}$ & $\mathrm{R}^{2}$ & $\mathrm{~F}$ & $\mathrm{P}_{\text {value }}$ & Keterangan \\
\hline $\begin{array}{l}\text { Koordinasi mata kaki }\left(\mathrm{X}_{1}\right) \\
\text { Keseimbangan }\left(\mathrm{X}_{2}\right) \\
\begin{array}{l}\text { Kekuatan otot tungkai }\left(\mathrm{X}_{3}\right) \\
\text { terhadap kemampuan } \\
\text { menggiring bola pada } \\
\text { permainan sepak bola }(\mathrm{Y})\end{array}\end{array}$ & 30 & 0,856 & 0,733 & 23,771 & 0,000 & Signifikan \\
\hline
\end{tabular}

$$
\begin{aligned}
& \text { Keterangan: } \\
& \mathrm{R}=\text { Koefisien regresi } \\
& \text { R2 = Koefisien determinan } \\
& \mathrm{F} \quad=\text { Nilai } \mathrm{F} \text { hitung } \\
& \text { Pvalue = Nilai Probabilitas } \\
& \mathrm{N}=\text { Banyaknya Data }
\end{aligned}
$$


Secara statistik hipotesis dapat dirumuskan sebagai berikut:

H_0:Rx_(1.2.) $\mathrm{y}=0$

H_1:Rx_(1.2.) y $\neq$

Berdasarkan hasil analisis regresi diperoleh nilai $\mathrm{F}$ sebesar 15,789. Sehingga hasil regresi yang didapatkan adalah signifikan. Dengan demikian perlu dilihat persamaan regresinya. Berdasarkan persamaan regresi $\hat{Y}=34,061+0,248 X 1+0,088 X 2+0,249 X 3$ dapat dikemukakan bahwa setiap peningkatan skor rata-rata koordinasi mata kaki, maka akan diperoleh menggiring bola pada permainan sepak bola sebesar 0,046X1, setiap dalam peningkatan skor rata-rata keseimbangan, maka akan diikuti oleh menggiring bola pada permainan sepak bola sebesar $0,035 \mathrm{X} 2$, setiap dalam peningkatan skor rata-rata kekuatan otot tungkai, maka akan diikuti oleh menggiring bola pada permainan sepak bola sebesar 0,035X3. Hasil analisis korelasi diperoleh nilai sebesar 0,734. Hal ini menunjukkan bahwa terdapat hubungan secara bersama-sama yang signifikan antara koordinasi mata kaki, keseimbangan dan kekuatan otot tungkai terhadap kemampuan menggiring bola pada permainan sepak bola siswa SMA Negeri 11 Makassar.

Setelah dilakukan uji persyaratan normalitas data pada hipotesis yang akan diuji, maka lebih lanjut dilakukan pengujian terhadap hipotesis, untuk membuktikan kebenarannya. Hasil perhitungan statistik yang dihipotesis penelitian diuraikan sebagai berikut.

1. Ada hubungan koordinasi mata kaki terhadap kemampuan menggiring bola pada permainan sepak bola siswa SMA Negeri 11 Makassar.

Dari hasil pengujian hipotesis pertama variabel menunjukkan ada hubungan yang signifikan antara koordinasi mata kaki (X1) terhadap menggiring bola pada permainan sepak bola (Y). Berdasarkan hasil perhitungan diperoleh nilai koefisien korelasi $(r)=-, 561$ yang dijelaskan melalui persamaan regresi $\hat{Y}=24,976+-439 \mathrm{X} 1$, sehingga dapat membuktikan bahwa teknik menggiring bola pada permainan sepak bola sangat membutuhkan komponen-komponen anggota tubuh seperti koordinasi mata kaki, dimana komponen-komponen tersebut sangat membantu dalam proses melakukan menggiring bola. Karena pada saat seseorang menggiring bola itu membutuhkan koordinasi mata kaki yang baik agar labih mudah dalam melakukan menggiring bola pada permainan sepak bola.

2. Ada hubungan langsung keseimbangan terhadap kemampuan menggiring bola pada permainan sepak bola siswa SMA Negeri 11 Makassar.

Dari hasil pengujian hipotesis kedua menunjukkan ada hubungan yang signifikan antara keseimbangan (X2) terhadap kemampuan menggiring bola pada permainan sepak bola (Y). Berdasarkan hasil perhitungan diperoleh nilai koefisien korelasi $(r)=-, 603$ yang dijelaskan melalui persamaan regresi $\hat{Y}=32,411+-175 \mathrm{X} 2$, sehingga temuan ini membuktikan bahwa dalam melakukan menggiring bola, keseimbangan merupakan faktor penunjang atau faktor pendukung dalam pelaksanaan menggiring bola pada permainan sepak bola. Keseimbangan ini berperan saat pemain mempertahankan posisi tubuh ketika sedang beregerak tanpa kehilangan keseimbangan atau kesadaran posisi tubuh pada saat menggiring bola pada permainan sepak bola.

3. Ada hubungan langsung kekuatan otot tungkai terhadap kemampuan menggiring bola pada permainan sepak bola siswa SMA Negeri 11 Makassar. 
Dari hasil pengujian hipotesis pertama variabel menunjukkan ada hubungan yang signifikan antara kekuatan otot tungkai (X3) terhadap menggiring bola pada permainan sepak bola (Y). Berdasarkan hasil perhitungan diperoleh nilai koefisien korelasi $(r)=-728$ yang dijelaskan melalui persamaan regresi $\hat{Y}=25,431+-356 \mathrm{X} 1$, sehingga dapat membuktikan bahwa teknik menggiring bola pada permainan sepak bola sangat membutuhkan dua komponen anggota tubuh seperti kekuatan otot tungkai, dimana komponen-komponen tersebut sangat membantu dalam proses melakukan menggiring bola. Karena pada saat seseorang menggiring bola itu membutuhkan kekuatan otot tungkai yang baik agar labih mudah dalam melakukan menggiring bola pada permainan sepak bola.

4. Ada hubungan koordinasi mata kaki, keseimbangan dan kekuatan otot tungkai secara bersama-sama terhadap kemampuan menggiring bola pada permainan sepak bola siswa SMA Negeri 11 Makassar.

Dari hasil pengujian hipotesis keempat menunjukkan terdapat hubungan yang signifikan antara koordinasi mata kaki (X1), keseimbangan (X2) dan kekuatan otot tungkai (X3) terhadap kemampuan menggiring bola pada permainan sepak bola (Y). Berdasarkan hasil perhitungan diperoleh nilai regresi $\mathrm{R}=0,856$ yang dijelaskan melalui persamaan regresi $\hat{\mathrm{Y}}=34,061+-248 \mathrm{X} 1$ $+-088 \mathrm{X} 2+-249 \mathrm{X} 3$, untuk nilai R2 (koefisien determinan) $=0,733$. Hal ini berarti 73,3\% menggiring bola pada permainan sepak bola, koordinasi mata kaki, keseimbangan dan kekuatan otot tungkai. Untuk sisanya $(100 \%-73,3 \%=26,7 \%)$ dipengaruhi oleh faktor lain. Didapat $\mathrm{F}$ hitung adalah 23,771, hasil ini semakin memperkuat hasil pengujian hipotesis pertama, kedua dan ketiga

\section{KESIMPULAN}

Berdasarkan analisis data dan pembahasan yang telah dikemukakan, maka hasil penelitian dapat disimpulkan sebagai berikut:

1. Ada hubungan yang signifikan antara koordinasi mata kaki terhadap kemampuan menggiring bola pada permainan sepak bola siswa SMA Negeri 11 Makassar.

2. Ada hubungan yang signifikan antara keseimbangan terhadap kemampuan menggiring bola pada permainan sepak bola siswa SMA Negeri 11 Makassar.

3. Ada hubungan yang signifikan antara kekuatan otot tungkai terhadap kemampuan menggiring bola pada permainan sepak bola siswa SMA Negeri 11 Makassar.

4. Ada hubungan yang signifikan antara koordinasi mata kaki, keseimbangan dan kekuatan otot tungkai terhadap kemampuan menggiring bola pada permainan sepak bola siswa SMA Negeri 11 Makassar.

\section{DAFTAR PUSTAKA}

Arikunto. 2013. Prosedur Penelitian, Suatu Pendekatan Praktik, Jakarta:Rineka Cipta.

Albertus fenanlampir dan Muhammad muhyi faruq. 2015. Tes Dan Pengukuran Dalam Olahraga. Yogyakarta: CV Andi Offset.

Atmojo, Mulyono Biyakto. 2015. Tes \& Pengukuran Pendidikan Jasmani/Olahraga. Surakarta: Penerbit UNS (UNS Press).

Bill Foran. 2021. Amir Supriadi. 2015. Jurnal. Hubungan Koordinasi Mata Kaki Terhadap Keterampilan Menggiring Bola Pada Permainan Sepakbola, PKO FIK Unimed. 
Batty C. Eric. 2014. Latihan Metode Baru Sepak Bola Serangan. CV. Pionir Jaya Bandung

Fankel dan Wallen. Kusumawati. 2015. Penelitian Pendidikan Penjasorkes Pendidikan Jasmani, Olahraga dan Kesehatan. Bandung: Alfabeta CF.

Halim. 2011. Akbar Hidayat. 2018. Jurnal. Pengaruh Daya Ledak Tungkai, Koordinasi Mata Kaki dan Keseimbangan Terhadap Kemampuan Shooting Ke Gawang Pada Permainan Sepakbola Siswa SMA Negeri 14 Sinjai

Harsono. 1988;1999. Aulia Ahmad Maulana. 2019. Jurnal. Kontribusi Kekuatan Otot Tungkai, Panjang Tungkai dan Keseimbangan Terhadap Kemampuan Menendang Bola Pada Permainan Sepakbola Murid SD Negeri Sungguminasa IV Kabupaten Gowa Sulawesi Selatan. Universitas Negeri Makassar.

Halim, Ichsan N. 2011. Tes Dan Pengukuran Kesegaran Jasmani. BP: Universitas Negeri Makassar.

Ismaryati Dkk. 2018.Tes Dan Pengukuran Olahraga. Surakarta: Penerbit UNS (UNS Press).

Kementerian Pendidikan dan Kebudayaan. 2014. Pendidikan Jasmani, Olahraga dan Kesehatan. Jakarta: Kementerian Pendidikan dan Kebudayaan.

Kusumawati. 2015. Penelitian Pendidikan Penjasorkes (Pendidikan Jasman, Olahraga)

Muhajir. 2014. Pendidikan Jasmani, Olahraga dan Kesehatan. Jakarta: PT. Gelora Aksara Pratama.

Mardalis. 2014. Metode Penelitian Suatu Pendekatan. PT. Bumi Aksara.

Nugraha Cipta Andi. 2016. Mahir Sepak Bola. Penerbit Nuansa

Rosdiana, Dini. 2014. Perencanaan Pembelajaran Dalam Pendidikan Jasmani dan Kesehatan. Bandung: Alfabeta CV.

Santoso. J dan Mellius. 2014. Teknik Dasar Bermain Sepak Bola. Cakrawala.

Sarumpaet, dkk. 2018 Siti Mafia. 2018. Jurnal. Kontribusi Kekuatan Otot Tungkai dan Kelincahan Terhadap Kemampuan Menggiring Dalam Permainan Sepak Bola pada Murid SDN 1 Sepakat

Sugiyono. 2016. Metode Penelitian Pendidikan, Pendekatan Kuantitatif, Kualitatif dan R\&D. Alfabeta, CV.

Sugiyono. 2015. Statistik Nonparametris Untuk Penelitian. Alfabeta, CV.

Saputra Nisco Aditya Rizky. 2016. Pengaruh Metode Bagian Terhadap Hasil Latihan Keterampilan Teknik Dribling Sepak Bola Peserta Ekstrakurikuler di SMA Muhammadiyah 7 Yogyakarta, Universitas Negeri Yogyakarta.

Teguh Susanto. 2016. Buku Pintar Olahraga. Yogyakarta: Pustaka Baru Press.

Widiastuti. 2017. Tes dan Pengukuran Olahraga. Depok: Penerbit PT Rajagrafindo Persada.

Widiastuti. 2019. Tes dan Pengukuran Olahraga. Jakarta: Rajawali Press. 